\title{
Borges: su poética y algunos poemas dedicados a escritores
}

\section{Borges: his poetry and some poems dedicated to writers}

DOI: https://doi.org/10.29166/tyc.v1i20.2166

\begin{abstract}
Mercedes Mafla
Ensayista, docente universitaria e investigadora ecuatoriana. Después de estudiar leyes en la Pontificia Universidad Católica del Ecuador (PUCE), obtuvo una Maestría en Filología Hispánica por el Consejo Superior de Investigaciones Científicas (España) y un Doctorado en Literatura, por la PUCE. Es parte del Comité Ejecutivo de Publicaciones del Centro de Publicaciones de la misma universidad. Ha publicado textos en las revistas Ulrika de Colombia, Hispamérica de Estados Unidos, Con/texto de Ecuador, Ómnibus de Chile, Espéculo: Revista de Estudios Literarios y en la sección Libros de los diarios El Comercio y Hoy de Quito. En 1998 prologó la selección de cuentos, Un extraño en el puerto, de Javier Vásconez publicada por Alfaguara de España.
\end{abstract}

Correo: mamafla@puce.edu.ec

\section{Resumen}

El presente trabajo se ocupará de realizar unas anotaciones generales sobre las manifestaciones explíitias de la poética de Jorge Luis Borges y, en especial, delineará la hipótesis de que, aunque el autor argentino siempre expresó sus ideas sobre la literatura en ensayos y ficciones por todos conocidos, también lo hizo, de una forma más velada, en muchos poemas que dedicó a variados escritores. Es pertinente señalar que los poemas que analizaremos en este ensayo tienen una característica adicional notable: contienen juicios críticos, puestos en escena por medio de varios recursos narrativos. Antes de entrar en el grupo de poemas dedicados a escritores, he creído pertinente hacer un escueto resumen del origen del arte poética, como un subgénero literario de antigua data, el mismo que se expresó en América Latina con bastante recurrencia, aunque con distintos fines: en su momento, como herencia directa de los clásicos (Horacio o Aristóteles) y, más adelante, como la manifestación de posturas individuales de asumir la poesía y la labor del poeta. En este contexto, Borges tiene la virtud de sintetizar la tradición y sus propias preguntas sobre su destino literario. Estos serán los asuntos a los que nos aproximaremos a continuación.

Palabras clave: Jorge Luis Borges, Ars Poetica, Literatura Latinoamericana, poesía.

\begin{abstract}
The present work will take care of making some general annotations on the explicit manifestations of Jorge Luis Borges' poetics and, especially, will outline the hypothesis that, although the Argentine author always expressed his ideas about literature in essays and fictions known by everyone. He also did it, in a more veiled way, in many poems that he dedicated to several writers. It is pertinent to point out that the poems that we will analyze in this essay have a remarkable additional characteristic: they include critical judgments, staged by means of various narrative resources. Before entering the group of poems dedicated to writers, I thought pertinent to make a brief summary of the origin of poetic art, as a literary subgenre of ancient history, the same which was expressed in Latin America quite frequently, although for different purposes: at the time, as a direct inheritance from the classics (Horacio or Aristotle) and, later, as the manifestation of individual positions to assume poetry and the work of the poet. In this context, Borges has the virtue of synthesizing tradition and his own questions about his literary destiny. These will be the issues that we will approach next.
\end{abstract}

Keywords: Jorge Luis Borges, Ars Poetica, Latin American Literature, poetry. 


\section{Introducción}

Es a Horacio (Venusia, 65 a.C.) a quien se le debe el poema Epistula ad Pisones, el mismo que, ya en la antigüedad, fue conocido como Ars Poetica, y que se convirtió en la fuente original de la teoría literaria occidental. Fue tan notable su influencia, que sus ecos atravesaron la Edad Media entera y llegaron hasta el Renacimiento. Junto a la Poética, de Aristóteles (casi invisible hasta el siglo XV), el poema latino forma el sustento de las preceptivas literarias. El académico español José Luis Pérez (2002) dice a propósito "Ambas obras se interpretaron -al menos desde los tratados teóricos, puesto que la realidad de las obras de creación era mucho más multiforme- como autorizadísimas fuentes de preceptos sobre los cuales edificar las nuevas literaturas nacionales, para que así fuesen equiparables a la literatura que el mundo grecolatino había legado" (p. 21). Horacio escribe un poema, en forma de epístola, una sutura o sátira, con fines didácticos, para trasmitir a los futuros poetas valiosas enseñanzas que, con el tiempo, se convirtieron en normas dignas de imitarse y en máximas tan prestigiosas como "la imitación, el decoro, el punto de vista, el afán de perfección, la necesidad de la crítica" (Pérez, 2002, p. 22).

Desde luego, las preceptivas literarias en la América Latina, especialmente las decimonónicas, tuvieron también como base las obras clásicas, sin embargo, era a través del ensayo crítico o filosófico y el manual o el tratado, que las enseñanzas sobre la literatura se materializaban. El poema, al estilo de Horacio, aparece también, aunque excepcionalmente1. Es, pues, Aristóteles quien prima. Pero, como ha señalado el estudioso mexicano Alberto Vital, en las primeras décadas del siglo XX, seis grandes poetas latinoamericanos (Vicente Huidobro, Alfonso Reyes, Pablo Neruda, Manuel Bandeira, Jaime Torres Bonet y Jorge Luis Borges) escriben poemas con idéntico título: "Arte poética". Esta coincidencia significativa hace pensar, al citado académico, que las vanguardias poéticas latinoamericanas habían desplazado, del territorio ensayístico o teórico, al del propio poema, el tema del sentido y de la forma de la poesía; es decir, en alguna medida, estaban nuevamente cerca de Horacio.

Los escritores mencionados escribieron sus poemas en un período de treinta años que coincide con el auge de las vanguardias; pero el de Borges es mucho más tardío, pues aparece en 1960. No obstante, todos acuerdan con la esencia del ars poética, en tanto tematizan la labor del poeta frente al poema, con la diferencia sustancial de que ellos ya no aspiran a trasmitir máximas universales, sino que se conforman con poner de manifiesto una visión más subjetiva y personal del tema. Hay que decir, en todo caso, que Huidobro² y Reyes ${ }^{3}$ están todavía

Uno de los ejemplos más conocidos en el siglo XIX es el poema “Ars” de José Asunción Silva, poema en el cual se sacraliza la poesía y en el que la visión romántica está presente. Ejemplo de ello son los versos iniciales: "El verso es vaso santo; poned en él tan sólo / Un pensamiento puro, / En cuyo fondo bullan hirvientes las imágenes / como burbujas de oro de un viejo vino oscuro". 
cerca del Romanticismo y del Modernismo y, en esa medida, sus poemas se parecen más al de Silva que a los de Neruda y Borges, quienes sí coincidieron en poner de manifiesto sus visiones completamente individuales sobre el arte que practicaban. Aunque ambos poetas, reconocidos como disímiles, se asemejan en este aspecto, pues sus "Arte poéticas" son declaraciones personales y, en el caso del chileno, una declaración no exenta de ironía y cierto sentimentalismo. Neruda escribe un poema confesional, autobiográfico, con tintes de patetismo, en el que se pinta a sí mismo, a la par que a su poesía ${ }^{4}$; Borges, en cambio, se presenta a través de sus obsesiones temáticas (especialmente la gran pregunta que atraviesa su obra, es decir, la naturaleza del Tiempo); pero, además, se disfraza y, de forma implícita, a través de un poema de rimas perfectas y propositivamente clásico, expresa su apego a las formas canónicas de la poesía. Disiente significativamente de los otros poetas mencionados (quizá menos de Neruda), en el hecho de considerar a la poesía como una paradoja, como "un triste oro [...] que es inmortal y pobre". Es importante destacar que el "Arte poética" de Borges se publicó en El Hacedor, que es el libro con el que el argentino vuelve a la poesía después de treinta y un años de la aparición de sus poemarios de juventud ${ }^{5}$. Quizá por ello le resultó necesario escribir un poema a través del cual se distanciaba de las vanguardias y, ciertamente, del joven Borges. A continuación, lo transcribo:

Arte poética

Mirar el río hecho de tiempo y agua y recordar que el tiempo es otro río, saber que nos perdemos como el río y que los rostros pasan como el agua.

Sentir que la vigilia es otro sueño que sueña no soñar y que la muerte que teme nuestra carne es esa muerte de cada noche, que se llama sueño.

Ver en el día o en el año un símbolo de los días del hombre y de sus sueños, convertir el ultraje de los años en una música, un rumor y un símbolo.

Ver en la muerte el sueño, en el ocaso un triste oro, tal es la poesía que es inmortal y pobre. La poesía vuelve como la aurora y el ocaso.

A veces en las tardes una cara nos mira desde el fondo de un espejo; el arte debe ser como el espejo que nos revela nuestra propia cara. Cuentan que Ulises, harto de prodigios, lloró de amor al divisar su Itaca

2 El poema de Huidobro tiene también algo del tono exaltado del escrito por Silva. Cito algunos versos: "Que el verso sea como una llave / Que abra mil puertas. / Una hoja que cae; algo pasa volando; [...] Por qué cantáis la rosa, ioh, poetas! / Hacedla florecer en el poema; / Sólo para nosotros / Viven todas las cosas bajo el sol. / El Poeta es un pequeño Dios".

3 El poema de Reyes, más escueto, coincide con los anteriores en su forma de sublimar la poesía como un acto casi divino. "Asustadiza gracias del poema: / flor temerosa, recatada en yema. / Y se cierra, como la sensitiva, / si la llega a tocar la mano viva. / Mano mejor que la mano de Orfeo, / mano que la presumo y no la creo, / para traer la Eurídice dormida / hasta la superficie de la vida”.

4 Arte poética: Entre sombra y espacio, entre guarniciones y doncellas, / dotado de corazón singular y sueños funestos, / precipitadamente pálido, marchito en la frente, / y con luto de viudo furioso por cada día de mi vida, / ay, para cada agua invisible que bebo soñolientamente / y de todo sonido que acojo temblando, / tengo la misma sed y la misma fiebre fría, / un oído que nace, una angustia indirecta, / como si llegaran ladrones o fantasmas, /y en una cascada de extensión fija y profunda, / como un camarero humillado,como una campana un poco rota, / como un espejo viejo, como un olor a casa sola / en la que los huéspedes entran de noche perdidamente ebrios, / y hay un olor de ropa tirada al suelo, y una ausencia de flores, / -posiblemente de otro modo, aún menos melancólico-, / pero, la verdad, de pronto, el viento que azota mi pecho, / las noches de sustancia infinita caídas en mi dormitorio, / el ruido de un día que arde con sacrificio / me piden lo profético que hay en mí, con melancolía / y un golpe de objetos que llaman sin ser respondidos / hay, y un movimiento sin tregua, y un nombre confuso.

5 Borges publicó Fervor de Buenos Aires en 1923, Luna de enfrente en 1925 y Cuaderno de San Martín en 1929. 
verde y humilde. El arte es esa Itaca de verde eternidad, no de prodigios.

También es como el río interminable, que pasa y queda y es cristal de un mismo

Heráclito inconstante, que es el mismo y es otro, como el río interminable

(Borges, 2019, p. 150).

Cabe abrir un paréntesis para señalar que, a pesar de ser Horacio quien inicia lo que para algunos es un subgénero literario (el del "arte poética”), la presencia explícita del poeta latino brilla por su ausencia en la obra poética de Borges. La estudiosa argentina Marcela Nasta (2007) ha recordado la obvia preeminencia de Virgilio y ha escrito al respecto:

Tan notable como la recurrencia virgiliana -en la producción literaria, en la disimulada poética de los prólogos, en el ámbito personal-, es el silencio que Borges guarda respecto de Horacio, a quien no menciona siquiera una vez en toda su obra poética [pero] las coincidencias entre Borges y Horacio se manifiestan en diversos planos [...] La primera de ellas consiste en que ninguno de los dos formuló una poética sistemática que diera cuenta de las estrategias y los recursos por ellos empleados en su producción literaria [...] El argentino sí reflexionó explícitamente y en términos teóricos acerca de sus propios hábitos y prácticas literarias [...] en los prólogos de sus libros de poesía, así como en un par de dedicatorias y epílogos (p. 218 ).

Creo que es pertinente añadir (y aquí expongo la hipótesis de este trabajo), que Borges, al igual que Horacio en sus Odas, suele exponer también su poética en los variados poemas que dedicó a muchos escritores. De regreso al poema "Arte poética”, debemos señalar que, además de la forma clásica en la que se presenta, y de la referencia al tiempo como la gran cuestión, Borges, a través de lo que llamaba "las secretas complejidades" que abundan en su obra, pone de manifiesto el componente ético de la poesía y, simultáneamente, insinúa una de sus máximas en relación a la literatura, aquella de que el Libro se escribe incesantemente y que los variados creadores no son más que distintos rostros del mismo Autor: "Heráclito inconstante, que es el mismo / y es otro, como el río interminable". En estas líneas podemos hallar también otra puerta hacia una de las características propias de muchos de los poemas de Borges (y de su obra entera, en realidad), me refiero, como ya anticipé, a la de poner en escena o dramatizar su poética usando los recursos de la narrativa, por ejemplo, cuando se refiere a sus autores más entrañables, evocados en su obra poética. Pero muchos de los poemas a los que me voy a referir se caracterizan, además, por ser verdaderos ensayos críticos encubiertos y, en esa medida, creo que es válido decir que Borges logra expresar su más secreta poética por medio de poemas híbridos, en los que, de alguna forma, logran convivir el Horacio del desiderátum y el Aristóteles de la poética. Es en estos poemas, especialmente, en donde encontramos al Borges sintético por antonomasia, no solo por la perfección formal de los versos, sino porque los poemas mencionados tienen el don de amalgamar el ensayo, el drama (entendido como diálogo) e incluso la más brillante crítica literaria. El arte poética de Borges, pues, está expresado a lo largo de su obra, explicitado, como sabemos, en sus célebres prólogos, pero adquiere una admirable originalidad, en sus poemas dedicados a escritores. De algunos de ellos se ocupará este trabajo. 


\section{Algunos poemas dedicados a escritores}

Quizá resulte inevitable continuar este ensayo sobre Jorge Luis Borges diciendo una obviedad: el gran tema de sus poemas, ensayos y cuentos es la literatura. Desde luego, todo libro habla de otros libros, unas veces secreta y otras explícitamente. Borges pertenece a los escritores que colocan en primer plano el tema y se deleita respondiendo a los escritores que lo han acompañado desde su infancia; observa bajo un microscopio el detalle recóndito de una página, relaciona, sin que medie un sentido temporal lineal, a los más variados y hasta opuestos poetas, ya sea por la persistencia de un símbolo o un tropo o por algún rasgo oculto, que el poder de la lectura ha devuelto a la vida. Pero, además, Borges usa sus extraordinarias dotes de lector para trasparentar sus juicios críticos e ir, a la par, confesando su poética. El incansable lector es, simultáneamente, el más agudo juez de su propia obra. Sus admirables prólogos son la muestra de su agudeza crítica, de sus lealtades literarias y una guía privilegiada de lecturas imprescindibles, entregada, por un maestro ameno y generoso, a sus lectores.

Voy a ocuparme de comentar algunos poemas, de la amplia serie que Borges dedicó a un variado grupo de escritores, a lo largo de sesenta años de creación poética. Cabe recordar que el escritor argentino insistió en que su poesía era una poesía intelectual, así lo dijo explícitamente en el prólogo de uno de sus libros finales; La cifra (1981). En él reconoce y, casi proclama, sus límites: la imposibilidad de la musicalidad osada, de la metáfora novedosa, de la exaltación y de la extensión desbordada. Igualmente en- tiende que lo intelectual de su poesía, asociado a la vigilia, a la "abstracción" (marcada por la erudición filosófica y literaria), se complementa con lo imprevisible del sueño, espacio de los mitos y fábulas esenciales. Recuerda Borges, en el mismo prólogo, que este camino lo marcaron, entre otros, escritores como Platón, en sus diálogos y el maestro indiscutible, Ralph Waldo Emerson, escritor fundamental para él, tanto que en uno de sus poemas narrativos finales, "Las hojas del ciprés" (Los conjurados, 1985) decide que el único libro que se llevará a la muerte será uno que escoge, al azar, de las obras completas del escritor norteamericano.

El componente intelectual de la poesía de Borges se manifiesta, entre otros, en su constante alusión a variados escritores y a sus obras. En el citado prólogo, Borges recuerda a Luis de León, como ejemplo de aquella poesía con pensamiento manifiesto: la poesía intelectual; pero, además, declara que, junto a la abstracción, él espera escribir también una poesía cuya música sea constante, una música secreta, sin la cual la poesía no sería tal. La búsqueda de este punto medio define la lírica del autor argentino, cuyo pensamiento es transparente, pero, al mismo tiempo, se expresa con la sonoridad tersa de un español preciso que se apega a las formas clásicas de composición, especialmente al soneto y sus conocidas exigencias formales.

Pensamiento (estético y ético) y música (quizá una que recuerde al latín, ha dicho el propio Borges) resumen mucho de la poética del argentino, el mismo que, me temo, no ha sido lo suficientemente valorado como poeta, basta mirar el libro recientemente publicado por la Real Academia de la Lengua en 
2017, el Borges esencial, para notar que la selección de poemas, frente a los cuentos y ensayos es francamente pobre.

Revisaré, entonces, algunos de los poemas en los que Borges se refiere a muchos de los escritores que lo han marcado y sobre los que tiene mucho que decir; escritores a los que también se refirió en ensayos y cuentos. Es pertinente recordar que, así como Borges elabora el soneto (tan apreciado en Quevedo, su gran maestro en español), se servirá de las enseñanzas del poeta inglés Robert Browning, de quien aprendió las vastas posibilidades de la poesía narrativa.

\section{Los novelistas}

Es conocida la desconfianza que a Borges le inspiraba la novela. Él mismo se encargó de bromear sobre el asunto. La abundancia y la desmesura no son cualidades que aprecia. Sus cuentos son prodigios de resumen, en tanto las historias pueden ser contadas sin dilación, de espaldas a la psicología o a las descripciones detalladas. Sin embargo, el primer poema sobre escritores que Borges escribió está dedicado a un novelista: Joseph Conrad. Se titula "Manuscrito hallado en un libro de Joseph Conrad" y aparece en 1925 en su segundo poemario, Luna de enfrente. Borges escribe, cuarenta y cuatro años después, el prólogo en el que dice de este libro: "No quiero ser injusto con él. Una que otra composición -El general Quiroga va en coche al muereposee acaso toda la vistosa belleza de una calcomanía; otras - Manuscrito hallado en un libro de Joseph Conrad- no deshonran, me permito afirmar, a quien las compuso. El hecho es que las siento ajenas; no me conciernen sus errores ni sus eventuales virtudes." (Borges, 2010, p. 61). A pesar de esta distancia, es claro que Borges va a ser leal a Conrad la vida entera. Lo menciona en su poema "La fama", de La cifra, 1981 en donde afirma "Ser devoto de Conrad" y, más significativamente aún, vuelve al novelista de los mares, en el esquivo y paródico epílogo de sus Obras completas editadas en 1996, en donde bromea sobre el Borges futuro, lector del Quijote, de quien dice: "Esta novela, por lo demás, fue una de las pocas que merecieron la indulgencia de Borges; otras fueron las de Voltaire, las de Stevenson, las de Conrad y las de Eca de Queiroz."

"Manuscrito hallado en un libro de Joseph Conrad", como todos los poemas dedicados a escritores, pertenece a la familia de la poesía intelectual que Borges escribe. El poema a Conrad prefigura la síntesis entre el artista, que se evoca poéticamente, y su obra: una síntesis entre la vigilia y el sueño, que será tema recurrente de la poesía del argentino. $\mathrm{Al}$ ser un primer intento, asistimos a un poema en el que la imagen se impone a la idea. Como sucede en los primeros poemas de Borges, hay una preeminencia del espacio. Los mismos nombres de los poemarios así lo anticipan: Fervor de Buenos Aires, Luna de enfrente.

En este poema inicial se dibuja al personaje en medio de un paisaje impresionista "En las trémulas tierras que exhalan el verano, / el día es invisible de puro blanco [...] Pero la antigua noche es honda como jarro / de agua cóncava. El agua se abre a infinitas huellas, / y en ociosas canoas, de cara a las estrellas, / el hombre mide el vago tiempo con el cigarro." (Borges, 2010, p. 72). En los versos finales se anticipa ya el tono reflexivo de la poesía por venir $\mathrm{y}$, siempre el tema del 
tiempo: "El mundo es unas cuantas tiernas imprecisiones. / El río, el primer río. El hombre, el primer hombre". No hay más que un leve boceto del mundo de Conrad, como si Borges se hubiese concentrado en captar el paisaje esencial del novelista polaco, en unos instantes de espera y contemplación. Conrad y sus personajes se confunden en el verso que dice: "El hombre mide el vago tiempo con el cigarro". Borges usará esta misma estrategia en sus poemas posteriores. Para ello su capacidad de síntesis se habrá aguzado y perfeccionado hasta la maestría.

No en vano han transcurrido treinta y cinco años hasta El Hacedor (1960), en donde publica algunos poemas con el tema que nos ocupa. Y transcurrirán cuarenta y cuatro años para la aparición de Elogio de la sombra (1969), poemario en el cual el tema del escritor y su obra será fundamental. En este poemario aparecen dos poemas sobre James Joyce. El tema ya había aparecido en otros escritos. Borges consideraba al irlandés un motivo para poner en escena su poética, a estas alturas (tenía ya sesenta y nueve años, había escrito sus piezas más celebradas: Ficciones o El Aleph-) todas abiertamente antibarrocas. "James Joyce" e "Invocación a Joyce" son los poemas a los que me remito. Antes de comentarlos, recordaré al momento pasado en el que Borges dictamina su primera sentencia sobre el Ulises; el mismo que data de 1936, solo catorce años después de la aparición de la célebre novela, a la que Borges menciona en su segundo cuento, publicado tímidamente en Historia de la eternidad, en 1936. Es el célebre "El acercamiento a Almotásim”. Dice, casi al final y en forma enigmática: "Los repetidos pero insignificantes contactos del Ulises de Joyce con la Odisea homérica, siguen escuchando - nunca sabré por qué- la atolondrada admiración de la crítica" (Borges, 1983, p. 278).

En el prólogo de El otro, el mismo (publicado en 1964) usa a Joyce como ejemplo del escritor que él mismo no ha querido ser. Es una declaración de principios que ha flotado en todo cuanto ha escrito hasta este momento, pero ahora dicha a plenitud. No se debe olvidar que en 1963 América Latina continuaba presa del concepto de vanguardia. Borges, en su madurez, ha crecido de espaldas a ella. Su camino personal ha sido el de un clasicismo jubiloso. Quedó lejos el fugaz ultraísmo y las ilusorias innovaciones de los modernismos. Dice en el mencionado prólogo:

Los idiomas del hombre -- son tradiciones que entrañan algo de fatal. Los experimentos individuales son de hecho, mínimos, salvo cuando el innovador se resigna a labrar un espécimen de museo, un juego destinado a la discusión de los historiadores de la literatura o al mero escándalo, como el Finnegans Wake o las Soledades [...] Es curiosa la suerte del escritor. Al principio es barroco, vanidosamente barroco, y al cabo de los años puede lograr, si son favorables los astros, no la sencillez, que no es nada, sino la modesta y secreta complejidad (Borges, 2010, p.163).

No obstante la crítica, en el soneto "James Joyce" (en Elogio de la sombra, 1969), Borges utiliza un método que ha perfeccionado: usa una forma narrativa para apropiarse del universo del escritor irlandés, en tanto ve en él una pregunta similar a la que a él mismo le ha fascinado siempre: el tiempo. La voz del poema empieza siendo neutra. Casi imita a la tradicional voz poética, aquella que simula una forma de la omnisciencia. Esta parte ma- 
yoritaria tiene un tono ensayístico en el que se afirma: "En un día del hombre están los días / del tiempo, desde aquel inconcebible / día inicial del tiempo" (Borges, 2010, p. 301). Pero en el verso que cierra la segunda estrofa aparece una primera persona: "el futuro, el ayer, lo que ahora es mío”, dice. Entonces, en el final (casi se podría decir en el desenlace), esa voz se intuye como la de los protagonistas del Ulyses, aunque también podría ser la de Joyce, tomando en cuenta que tanto Leopold Bloom como Stephen Dedalus se consideraron sus alter egos y, desde luego, la del mismo Borges que transforma en conmovedora plegaria el pensamiento del personaje al que le hace decir: "Dame, Señor, coraje y alegría / para escalar la cumbre de este día”.

"Invocación a Joyce" (también en Elogio de la sombra) es diferente. El poema es largo y la voz poética está claramente identificada con la de Borges. En la primera parte, ésta habla desde el nosotros, que une a los artistas de aquella vanguardia unánime. La crítica se transforma en autocrítica afectuosa a los artistas que confiaron en un destino adánico, léase vanguardista: "jugábamos a ser el primer Adán / que dio nombres a las cosas”, dice Borges. Más adelante vuelve a su visión definitiva, la que asume la posible inutilidad o arrogancia de la tarea puramente experimental del arte: "Fuimos el imagismo, el cubismo", dice, y nosotros asumimos que en la larga lista de ismos se puede recordar el ultraísmo con el que Borges estuvo tempranamente en contacto en España, guiado por su amigo Rafael Cansinos-Assens. Al mirar de lejos las corrientes vanguardistas, dictamina, con la sabiduría conocida, que muchos de estos proyectos se convertirían, como de hecho sucedió, en "conventículos y sec- tas/ que las crédulas universidades veneran". Pero aparta a Joyce del resto, lo exalta e invoca con paradójica admiración. Los años han matizado la primera desconfianza. Ahora Borges dice de Joyce: “Tú, mientras tanto, forjabas / en las ciudades del destierro, en aquel destierro que fue / tu aborrecido y elegido instrumento, el arma de tu arte, / erigías tus arduos laberintos, infinitesimales e infinitos, / admirablemente mezquinos, / más populosos que la historia." Más adelante, exalta, nuevamente, el valor y él mismo se mira como un cobarde (algo en lo que insistía en sus entrevistas). Unido aun al nosotros dice: "Qué importa nuestra cobardía si hay en la tierra / un solo hombre valiente, [...] qué importa mi perdida generación, / ese vago espejo, / si tus libros la justifican".

De entre los novelistas anglosajones, Borges escribe además poemas sobre Melville y Stevenson. El largo poema "Herman Melville" aparece en La moneda de hierro (1976) y se emparenta con los dedicados a Conrad y Stevenson, en tanto los tres frecuentan la novela de aventuras y viajes marítimos. En el caso de Melville, Borges hace una auténtica apología. El lector y admirador trabajan junto al poeta. Una pista erudita permite a Borges hallar un origen insospechado de la mítica ballena. En uno de los versos dice sobre el escritor norteamericano: "Siempre lo cercó el mar de sus mayores, / los sajones, que al mar dieron el nombre / ruta de la ballena, en que se aúnan / las dos enormes cosas, la ballena / y los mares que largamente surca" (Borges, 2010, p. 448). El hallazgo tiene el encanto de un secreto develado. ¿Conocería Melville esta metonimia? Si no es así recordamos el papel esencial que un lector tan extraordinario como Borges tiene en la 
transformación de cuanto lee. Nuevamente el personaje y el héroe (Ahab y Melville) se funden y se transforman en metáfora del viajero. Estos versos lo atestiguan: "Hombre, se dio a los mares del planeta / y a las agotadoras singlaturas / y conoció el arpón enrojecido / por Leviathán y la rayada arena / y el olor de las noches y del alba / y el horizonte en que el azar acecha / y la felicidad de ser valiente / y el gusto, al fin, de divisar Ítaca”.

\section{Los argentinos}

Tres poemas les dedica Borges a los escritores argentinos: uno a Ricardo Güiraldes, otro a Manuel Mujica Láinez y el tercero Hilario Ascasubi. El primero aparece en 1969 en Elogio de la sombra y es un soneto de homenaje personal. Lo que destaca el poema son las cualidades personales del padre de Segundo Sombra: su cortesía, su serenidad y su amor por la música: "Nadie podrá olvidar su cortesía [...] la primera / forma de su bondad, la verdadera / cifra de un alma clara como el día” (Borges, 2010, p. 305). Pero además Borges interpone el tiempo, entre el viejo escritor de la pampa y él mismo. El Poeta es uno solo. En el pasado se llamó Güiraldes; hoy Borges: "Como en el puro sueño de un espejo / (tú eres la realidad, yo su reflejo) / te veo conversando con nosotros". El futuro, la muerte son para el novelista "el abierto / campo de ayer, el alba de los potros", es decir el regreso al origen.

En La moneda de hierro (1976) escribe “A Manuel Mujica Láinez". El tono ensayístico es determinante, pero además Borges se compara con el aristocrático autor de novelas tan asombrosas como Bomarzo (1962), El unicornio (1965) o El laberinto (1974). Borges empieza reafirmando una de sus ideas más usuales: "la eterna Escritura / tiene tantos sentidos como lectores. Cada / versión es verdadera y ha sido prefijada / por Quien es el lector, el libro y la lectura" (Borges, 2010, p. 445), sentencia e inmediatamente compara la "versión de la patria" del amigo, con la suya propia. Parecería que Borges prefiere referirse a la obra quizá menos relevante del colega, que a novelas como las que he mencionado. No se puede perder de vista el año de publicación del poema: 1976 que es el año del golpe militar en Argentina. Entonces el tema del poema parecería ser el valor y la tierra de origen, es decir la ética ante el totalitarismo ¿Cómo lo trató Mujuca Lainez? Borges responde: “Tú versión de la patria, con sus fastos y brillos, / entra en mi vaga sombra como si entrara el día / y la oda se burla de la Oda. (La mía / no es más que una nostalgia de ignorantes cuchillos / y de viejo coraje)". El final del poema es, por otra parte, desolador. La pregunta suena retórica: "Manuel Mujica Lainez, alguna vez tuvimos / una patria -¿recuerdas?- y los dos la perdimos".

El soneto dedicado a Ascasubi (igualmente publicado en La moneda de hierro) esconde también una oculta desolación por el estado de la política argentina. Borges siempre se consideró un anarquista; solía repetir que sus conciudadanos no le entendían porque él no era peronista, ni comunista, ni populista. Hilario Ascasubi es recordado por ser un poeta gauchesco. Es necesario señalar el gran interés que Borges le concedió al estudio de esta poesía. Su estudio sobre el Martín Fierro es la prueba más conocida, aunque también cabe mencionar el poemario Para las seis cuerdas (1965) en el cual ensaya varias milongas inspiradas en 
la poesía de los compadritos, los gauchos y los cuchillos. Ascasubi fue un soldado que enfrentó a Rosas, quien para Borges representa el mismo mal que Perón y su herencia. De una manera subliminal, Borges compara el mundo del poeta muerto con los años terribles que vive su país en ese entonces. Lejos queda la felicidad de una Argentina de pampas y valientes y modestos hombres. El valor vuelve a ser glorificado. La voz poética es crítica y, como en el poema a Mujica Lainez, se identifica plenamente con el propio Borges. "Alguna vez hubo una dicha. El hombre / aceptaba el amor y la batalla / con igual regocijo", dice. El presente es distinto. Con una claridad que suena a proclama, Borges exclama: "La canalla / sentimental no había usurpado el nombre / del pueblo." Ascasubi ha sido traicionado. La "aurora" de la patria ha sido "ultrajada". El héroe que cantaba y luchaba no existe más. Argentina está poseída por el odio.

La admiración de Borges por Ascasibi viene de lejos. En su primer libro de ensayo Discusión (1932) lo reivindica. Más que considerarlo un "precursor borroso de Hernández", le da un poder creativo superior al clásico de la poesía gauchesca. Mientras Hernández tenía un fin "limitadísimo: la historia del destino de Martín Fierro referida por éste. No intuimos los hechos, sino al paisano Martín Fierro contándolos" (Borges, 2010, p. 192). Borges le critica a Hernández su desinterés por el mundo del personaje, por sus detalles y colores. Es en esta prolijidad en la que considera a Ascasubi superior. Dice sobre Hernández: "los muchos bailes que necesariamente figuran en su relato no son nunca descritos. Ascasubi, en cambio, se propone la intuición directa del baile, del juego discontinuo de los cuerpos que se están entendiendo”. En el poema del futuro, Borges alaba la multiplicidad de Ascasibi (hay que recordar que escribía con varios seudónimos). Dice: "Fue muchos hombres. Fue el cantor y el coro; / por el río del tiempo fue Proteo". Pero en el presente, la leyenda del valiente ha terminado y concluye el poema con una dolorosa sentencia: "Hoy somos noche y nada”.

\section{Los poetas españoles}

El primer poema que Borges le dedica a un poeta es el que escribe sobre Quevedo en El Hacedor (1960). Se titula "A un viejo poeta" y así da inicio a una prolongada declaración de lealtad y admiración, y convierte al poeta español en el Virgilio de cuya mano vuelve a la poesía, después de décadas. El soneto en cuestión ubica a Quevedo mientras camina por Castilla, sin siquiera verla. Borges lo imagina abstraído, tratando de comprender "Un intrincado / versículo de Juan [que] es tu cuidado" (Borges, 2010, p. 127). Seguramente el versículo es: "Al principio existía la Palabra y la $\mathrm{Pa}$ labra estaba junto a Dios, y la Palabra era Dios”, porque Borges sabe que Quevedo es el poeta del pensamiento, por antonomasia. Diez años antes en Otras inquisiciones había escrito: "La grandeza de Quevedo es verbal”, "Quevedo [...] todo lo salva, o casi, con la dignidad del lenguaje", "Las mejores piezas de Quevedo [...] No son oscuras; eluden el error de perturbar, o de distraer, con enigmas, a diferencia de otras de Mallarmé, de Yeats y de George. Son [...] objetos verbales, puros e independientes como una espada o como un anillo de plata" (Borges, 1983, p 342). 
"A un viejo poeta" no nombra a Quevedo directamente, solo al final, cuando se cita el famoso verso de su poema "Memorial inmortal de Don Pedro Girón, Duque de Osuna, muerto en prisión" que dice: "Y su epitafio la sangrienta luna", se entiende que es de Quevedo de quien se habla. Y Quevedo camina, mientras piensa. Borges lo ve a través del tiempo y repara en que el poeta ignora el paisaje. "y apenas reparaste en la amarilla / puesta del sol", le dice en tono apelativo. A Quevedo el paisaje no le habla, como lo hará más tarde a los románticos. Él piensa en la Palabra, no obstante, Borges, en el mencionado ensayo llamado justamente "Quevedo", dice que la obra poética de Quevedo "Comprende pensativos sonetos, que de algún modo prefiguran a Wordsworth", Tal vez porque el poeta inglés intuía que su visión de la naturaleza era una ilusión.

A propósito de otros poetas españoles, Borges usa la palabra "cuidado" como "temor", y hace así un homenaje a la palabra usada por dos de los poetas españoles fundamentales: Fray Luis y San Juan. El primero la usa en "Vida retirada": “¿Qué presta a mi contento, / si soy del vano dedo señalado, / si en busca de este viento / ando desalentado / con ansias vivas, y mortal cuidado?” y San Juan; en la estrofa final de "La noche oscura del alma": "cesó todo, y dexéme / dexando mi cuidado / entre las azucenas olvidado". Cabe señalar que Borges menciona a ambos poetas con admiración. En "España”, (El otro, el mismo) dice: "estás España silenciosa, en nosotros [...] España del Islam, de la cábala / y de la noche oscura del Alma”. A Fray Luis lo menciona especialmente en el hermoso prólogo de La cifra (1981) en donde da cuenta de su contacto con la poesía "intelectual”. Dice:
"Ejemplo de poesía intelectual es aquella silva de Luis de León, que Poe sabía de memoria: "Vivir quiero conmigo, / gozar quiero del bien que debo al Cielo, / a solas, sin testigo, / libre de amor, de celo, / de odio de esperanza, de recelo" (Borges, 2010, p. 163).

En 1964, Borges escribe su libro de poesía más significativo: El otro, el mismo y más que ningún otro poemario, éste es un auténtico paseo por la literatura que el maestro ha frecuentado toda su vida. Junto a las loas, homenajes, sintéticos ensayos que esconden estas piezas, hay algunos otros que, como en los ejemplos señalados antes, también aparecen verdaderos ajustes de cuentas o críticas a poetas y a poéticas que Borges no aprecia. El caso más elocuente es el poema "Baltazar Gracián”, quizá el más duro que haya escrito sobre poeta alguno. La voz es nuevamente narrativa y es la del propio Borges, enmascarado como "voz poética". La dura crítica empieza equiparando la poesía del poeta barroco a un juego en la nada. El uso de la retórica, entendida como el abuso y el vaciamiento del lenguaje, es la primera prueba en este implacable juicio: "Helada y laboriosa nadería, fue para este jesuita la poesía, / reducida para él a estratagemas" (Borges, 2010, p. 189). ¿De dónde viene esta incapacidad? Borges da una respuesta fatal: "No hubo música en su alma", sentencia y abunda en consideraciones éticas: "la veneración de las astucias / y el desdén de lo humano y sobrehumano". Es decir, el juicio a Gracián es inevitablemente estético y ético. Pero además hay agravantes: Gracián, según Borges, no estaba movido por la "antigua voz" y no solo se refiere a la distancia entre Gracián y Homero o Virgilio, sino a la incomprensión del profundo misterio de la muerte de Cristo. Doble crí- 
tica entonces: ética y estética. ¿Qué surge de la impostura? Un adefesio, dice Borges echando mano de su célebre habilidad para el humor maledicente. Gracián al ver las estrellas las "apodó con palabra pecadora / gallinas de los campos celestes". Gracián muere en la quinta estrofa del poema, que se pone vagamente narrativo y el contador se imagina el encuentro entre el pedestre Gracián (siempre según Borges) con la gloria. Lo imagina sorprendido ente el fulgor de "los Arquetipos y Esplendores", ante "el inexorable / sol de Dios, [...] La Verdad”. Pero en la última y lapidaria estrofa conjetura un final sin gloria: "Sé de otra conclusión. Dado a sus temas / minúsculos, Gracián no vio la gloria / y sigue resolviendo en la memoria / laberintos, retruécanos y emblemas”.

La vehemencia crítica de este poema me ha hecho pensar que Borges vio en el poeta español un perfecto modelo de todo cuanto él mismo desdeñaba de alguna escritura, no precisamente pasada, sino quizá muy presente para él. ¿̇El experimentalismo extremo de las vanguardias le habrá llevado a Borges a comparar la palabrería preciosista y muchas veces vacua de Gracián con la naciente retórica en la que todo valía? ¿Las "gallinas de los campos celestiales" no se asemejen formalmente a los saltos al abismo tantos barroquismos latinoamericanos? Quizá. Y aunque nunca he entendido del todo el malestar que a Borges le causaba la retórica especialmente surrealista, hoy creo entender que él vio en el método un camino que, aunque redefinió la libertad creativa, también abrió una puerta al exceso y a la vacuidad. Hablo de su estela decadente que aun hoy enmascara la falta de rigor en repetitivas argucias.

Tal vez para contribuir a descifrar estas veladas alusiones críticas, el poema
"Rafael Cansinos-Assens" puede ayudar. También fue publicado en El otro, el mismo y este soneto hace referencia, como ya he dicho anteriormente, al amigo y maestro de juventud de Borges, gracias a quien importó desde España el ultraísmo. Borges conoció a Cansinos-Assens en su juventud, pero lejos de hacer una posible apología nostálgica o sentimental de este encuentro que fue definitivo para ambos, le dedica a su maestro un poema en el que lo aparta de la juventud entusiasmada por el futurismo y su consecuencia, el ultraísmo, y celebra la devoción de Cansinos-Assens por su cultura judía, a la que consagró amplios estudios y traducciones. No se puede desconocer la paradoja: aquel llamado a ser recordado como el guía de la innovación, termina siendo festejado como un hijo de Israel, fiel a su amor por el Libro. Borges no usa el evocativo. Lo presenta en segunda persona. Hace un retrato espiritual: "Bebió como quien bebe un hondo vino / los Psalmos y el Cantar de la Escritura / y sintió que era suya esa dulzura / y sintió que era suyo aquel destino. / Lo llamaba Israel" (Borges, 2010, 225).

En 1985, un año antes de su muerte, sucedida el 14 de junio de 1986, Borges publicará su último poemario: Los conjurados. La muerte está presente en él. Muchos amigos y amores se han ido y de ellos el poeta se despide negando la muerte, cantando el porvenir sostenido en los hombros de los conjurados, aquellos que se han reunido para proteger el mundo. No hay casi escritores ya a quienes referirse (salvo un canto al inolvidable Sherlock Holmes); pero muy significativamente, Borges escribe un duro poema titulado "Góngora". Este es el último poema dedicado a un escritor. El camino comienza con Quevedo y se termina con Góngora. 
Es el mismísimo Góngora quien habla, más bien se confiesa, incluso podría decirse que Borges le hace arrepentirse de algunas cosas. La crítica está implícita y es tan arriesgada como la que solo un anciano sabio o caprichoso, en vísperas de la muerte puede proferir sin temor. ¿Cuál es la confesión? ¿El paganismo? "Marte, la guerra. Febo, el sol, Neptuno, / el mar que ya no pueden ver mis ojos [...] Tales despojos / han desterrado a Dios, que es Tres y es Uno / de mi despierto corazón" (Borges, 2010, p. 623) le hace decir. Más aún: le ha faltado individualidad. No en vano la preferencia de Borges por el temible Quevedo, contradictorio y conmovedor. En cambio, el Góngora de Borges se asume: "Cercado estoy por la mitología. / Nada puedo. Virgilio me ha hechizado. / Virgilio y el latín”, dice.

Y más adelante, lo que Borges ya ha dicho: su oposición a la retórica de la opacidad: "Hice que cada / estrofa fuera un arduo laberinto / de entretejidas voces", continúa el Góngora del argentino. Pero finalmente el personaje se engrandece y en estos versos, Borges (como los llamados poetas del 27) se reconcilia e identifica con el andaluz orgulloso: "Tal es mi extraño oficio de poeta. / ¿Qué me importan las befas y el renombre?". Es decir que es la dignidad de la vida y no la vana complejidad del barroco gongorino lo que Borges aprecia del poeta.

Si desde la época de la Colonia hasta el neobarroco, Góngora ha sido el santo patrono de la poesía latinoamericana, resulta difícil no entrever una crítica a toda esta larga línea de sucesión. Borges está fuera de la corriente, quizá por ello en el poema "Góngora" le haga decir finalmente al personaje: "Quiero volver a las comunes cosas: / el agua, el pan, un cántaro, unas rosas..." "las comunes cosas" o las palabras usuales son las que mejor cifran la diáfana poesía borgiana, frente a la apabullante mayoría gongorina. No en vano Quevedo es el poeta en español que acompaña a Borges hasta el final. Cito nuevamente, y para terminar, el epílogo de las Obras completas de 1996 en el cual queda definida la relación de Borges con las letras españolas. Usando la voz de un supuesto biógrafo futuro, dice con sabiduría y humor, acerca de sí mismo "Sus preferencias fueron la literatura, la filosofía y la ética. Prueba de lo primero es lo que nos ha llegado de su labor, que sin embargo deja entrever ciertas incurables limitaciones. Por ejemplo, no acabó nunca de gustar de las letras hispánicas, pese al hábito de Quevedo”. 


\section{Bibliografía}

Borges, Jorge Luis. Obras completas. 1923-1985. Buenos Aires: Emecé Editores, 1983.

Borges, Jorge Luis. Obra poética. Buenos Aires: Emecé Editores, 2010.

Nasta, Marcela. "Horacio en la obra poética de Jorge Luis Borges: un silencio elocuente". Revista de la Universidad de Buenos Aires, 76, 2007, pp. 217-225.

Pérez Pástor, José Luis. "La traducción del licenciado Francisco de Cascales del Ars poética de Horacio". Criticón, 86, 2002, pp. 21-38.

Vital, Alberto. "Arte poética en seis poetas latinoamericanos del siglo XX. Alfonso Reyes, Vicente Huidobro, Jorge Luis

Borges, Manuel Bandeira, Pablo Neruda y Jaime Torres Bodet". Criticón, 96, 2006, pp. 37-62. 